\title{
APPLICATION OF MODERN WAREHOUSE TECHNOLOGY IN THE SLOVENIAN AUTOMOTIVE INDUSTRY
}

\author{
Sebastjan Škerličำ, Robert Muha ${ }^{2}$, Edgar Sokolovskij ${ }^{3}$ \\ ${ }^{1,2}$ Faculty of Maritime Studies and Transport, University of Ljubljana, Slovenia \\ ${ }^{3}$ Dept of Automobile Engineering, Vilnius Gediminas Technical University, Lithuania
}

Submitted 18 April 2017; resubmitted 22 June 2017; accepted 28 June 2017

\begin{abstract}
The objective of this paper is to demonstrate the usefulness and reliability of modern warehouse technology for suppliers in the automotive industry and to identify the potential causes preventing it from being used more in practice. In recent years, we have seen great progress made in the development of modern warehouse solutions, as well as a dramatic rise in research on the issues related to the introduction of modern technology and interaction between operators and automation. However, a look at some of the existing studies on the usefulness of the use of modern technology reveals that their conclusions are often contradictory. The results of statistical analysis of Slovenian companies that operate as suppliers in the international automotive industry show that modern warehousing technology is reliable and safe to use, but more than $60 \%$ of companies fail to take advantage of its benefits. These companies are also using basic warehouse technology, despite the fact that such technology does not ensure a sense of safety in the warehouse. In the medium term, this could put them at a disadvantage against competitors in the demanding sector of the automotive industry. The results of the study provide additional starting points for understanding human use of modern warehouse technology, which can lead to improvements in how warehouse systems are designed, more effective employee training methods and a reasonable and balanced policy for the automation of the warehousing processes.
\end{abstract}

Keywords: modern warehouse technology; human-automation interaction; warehouse technology analysis; reliability analysis; automotive industry; case study.

\section{Introduction}

Warehousing operations are very intense and characterised by the constant movement of people and equipment (Myerson 2012; Mangan, Lalwani 2016; Kłodawski et al. 2017; Bohács et al. 2013; Apsalons, Gromov 2017; Kolarovszki et al. 2016; Nathanail et al. 2016; Dybskaya, Sverchkov 2017; Palšaitis et al. 2017; Pyza et al. 2017). These operations are not solely value-adding for the company's business system, since every additional activity in the warehouse increases costs and potentially the occurrence of errors in the warehousing process. This prompts companies to attempt to upgrade their existing technical tools and introduce new modern technological solutions, in order to increase productivity and quality of work, which should lead to a reduction of errors in the warehousing process (Rekik et al. 2008). The benefits of the use of modern technologies in the warehousing work process include a better use of space, savings in energy and manpower, improved control, fewer manual handling operations, the possibility of coordinating flows of products in order to avoid bottlenecks, reduced

operational costs and fewer work related accidents (Richards 2014).

On the other hand, the warehousing process is changing, because the increased use of automation results in fewer manual handling operations, but at the same time, it increases data processing. Thus, warehouse operators are now dealing with information more often than with the physical movement of goods (Mangan, Lalwani 2016). These changes in warehousing operations mean that there are fewer errors in terms of the movement of goods, but they also give rise to a series of different types of errors that are associated with an increased use of technology (Reason 1997).

The introduction of automation in the warehouse process is therefore linked to differing perceptions of its usefulness. Differing views on the presented scientific problem raise two fundamental inconsistencies in managing warehousing operations from a cost, technological, safety and organisational perspective. Companies that fail to recognise the benefits of an effective use of

Corresponding author: Sebastjan Škerlič

E-mail: sebastjan.skerlic@fpp.uni-li.si 
modern technology in the warehouse process will find it more difficult to adapt to modern customer needs in the supply chain. An unbalanced and non-systemic use of warehouse technologies, especially in those operations that do not necessarily require the use of modern warehouse technology, can also have a negative effect.

Each production industry has different requirements and specifics regarding the technological equipment of a warehouse. Companies in the automotive industry that are subject to constant demands for quality processes and innovative solutions (Kajackas et al. 2015), are even more focused on finding the optimal ratio between the best use of resources in the warehouse process and satisfying customer needs. While companies can introduce modern technological solutions into every warehouse operation, the question remains whether such investments lead to a better quality of work in a warehouse as well as a decrease in the number of errors.

The lack of a consistent position regarding the use of automation can bring forth differing perceptions on the usefulness of introducing modern technology in the various warehouse process operations. To this end, a survey was conducted on a sample of 24 Slovenian supply companies in the automotive industry, which have more than 14000 employees and generate total of 2.2 billion EUR in annual revenue. Based on the presented scientific problem, the objective of this study is to analyse the usefulness and reliability of modern warehouse technology for suppliers in the automotive industry and to identify the potential causes preventing it from being used more in practice.

The actuality of the field of research dealing with the implementation of modern technological solutions and searching for optimal interaction between humans and automation was highlighted by Tsarouchi et al. (2016). The authors of the study determined that, during the period from 1980 to 1989 , only 67 studies were published on the subject, while from 2010 to 2015, the number rose to 3153 . This number indicates that this is a very topical issue for research, especially in light of the great progress made in recent years in the field of development of modern warehouse solutions. However, there is a lack of studies that would offer a complete picture of how companies in the automotive industry are taking advantage of modern warehouse technology, in terms of frequency of use, ensuring safety and the successful interaction between operators and warehouse technology. Thus, the study builds upon the existing scientific literature and sets important guidelines for companies in the Slovenian automotive industry, with regard to the necessary improvements in the design of warehouse systems and a reasonable and balanced policy for the automation of warehousing processes.

\section{Literature Review and Formulation of the Research Model}

The introduction of technology in warehouse and distribution management has effectively changed how many employees conduct their jobs. Owing to the high-degree of automation, many information collection and distri- bution tasks that were once necessary were now under total automation of the Warehouse Management System (WMS) and other contemporary warehousing solutions (Berger, Ludwig 2007). Automation in warehouses refers to both material handling solutions and ICT-based devices. Due to the development and popularity of information and automation technologies, the logistics industry has gradually implemented automation or semi automation to support different warehouse operations (Marchet et al. 2015). The main purpose of automating the warehouse system is to control the movement and storage of the products, together with the benefit of enhanced security and quicker handling (Atieh et al. 2016). The authors bring attention to the following modern technology solutions in the warehousing process: WMS, Radio Frequency IDentification (RFID), Voice picking technology $(\mathrm{PbV})$ and Light picking technology $(\mathrm{PbL})$. Modern warehouse technology also includes the following warehouse equipment: stacker crane, horizontal/vertical carousel, Automated Guided Vehicle (AGV) and Automated Storage and Retrieval Systems (AS/RS). The advantages of WMS, RFID, $\mathrm{PbV}, \mathrm{PbL}$ and AS/RS will be presented in more detail, as they have the biggest impact on the efficiency of the warehouse process.

WMS is a necessary approach for every warehouse. An automated warehousing system provides less effort and more efficient and reliable results, compared to a manual handling system. WMS is designed to help reduce costs through effective warehouse processes (Atieh et al. 2016). Min (2006) points out that the use of WMS is one of the proactive ways to speed up order turnaround time, improve inventory accuracy, provide instant order status information, manage warehouse space and enhance labour productivity.

A growing number of organisations around the world are considering the implementation of RFID systems to improve their business and operations processes. RFID is also considered to be the next step in supply chain management, as it can increase operational efficiency through the sharing of real-time information and the tracking and tracing of goods, and can enable total visibility in the supply chain (Ngai et al. 2010). A typical RFID system includes transponders (tags) and interrogators (readers): tags are attached to objects/persons, and readers communicate with the tags in their transmission ranges via radio signals (Xiao et al. 2007). Advantages over conventional identification methods such as barcoding include the ability to read tags without line of sight, the ability to read multiple tags concurrently, and the ability to store and change information on an RFID tag. In recent years, companies have started using this technology in many areas of operations management and beyond. Potential applications of RFID include retail operations, inventory control and logistics, manufacturing, configuration management, authentication, counterfeit protection and security (Gaukler, Seifert 2007). Tajima (2007) made a conclusion about the strategic value of RFID in supply chain management and five prominent strengths were stated: reduced shrinkage, reduced material handling, increased data accuracy, faster exception management and improved information shar- 
ing. Because of these strengths, RFID technology is a potential successor to barcoding and could complement or completely replace it in the future (Schmidt et al. 2013).

$\mathrm{PbV}$ is a technology that makes use of audio and voice control to guide the picking process. The picker wears a headset that is connected to a small terminal that can be attached to his or her belt. This terminal communicates wirelessly with the WMS. Through the headset, the picker is informed of the location of the next item that has to be picked. The picker confirms the location through mentioning a unique check digit through the microphone, and then confirms the quantity of items picked. This process repeats itself until the order is completed and the next order is started (De Vries et al. 2016). The primary advantage of voice picking is that pickers are hands-free - which is particularly useful if there are heavy products to be handled - and eyes-free, supported by headsets with an attached microphone. This can increase productivity by 10-15\% (Marchet et al. 2015).

$\mathrm{PtL}$ is a picking technology that supports the pickers with light signals. This technology is frequently applied in item picking applications, where pickers retrieve items from gravity flow racks or shelves. A display with a light is attached to each storage location, lighting up when a product has to be picked from the particular location. The required quantity is shown on the display, and pickers confirm the pick by pressing a button. They continue working on an order until all lights have been turned off, after which a next order can be started (De Vries et al. 2016). Pick-to-light systems help enhance productivity (up to 50\%), decrease picking errors and simplify personnel training, thus reducing operational costs (Marchet et al. 2015).

The most common technology for the automated transportation of loads in the warehouse is AS/RS, which have been integrated into many warehouses and distribution centres so far. Each type of AS/RS can be customized for the required system design and will benefit the material handling process by reducing labour costs, storage footprint, and time required to store and retrieve items from the storage locations. In addition, AS/ RS allows to achieve high inventory optimization and tracking level and increase overall system performance (Janilionis et al. 2016).

On the other hand, authors who study human-automation interaction and application of modern technology to ensure the reliability of business operations, have differing views. The studies that were conducted in the past have one thing in common - they all concluded that the use of modern technology does not reduce the potential for human error, but merely creates the potential for errors of a different kind (Bainbridge 1983; Norman 1990; Dekker 2017; Reason 2009). The dilemmas that accompany the introduction of modern technologies and their impact on the work of operators were confirmed by recent studies. However, modern authors focus mainly on studying the various aspects of interaction between humans and automation, either by searching for reasons for improving the process of introducing automation, or by developing specific methodological approaches to regulating this field.

De Felice and Petrillo (2011) suggest that, with the development of technology and safety systems, human error has become the most significant source of workplace accidents. They have also developed a methodological approach for improving reliability in railway transportation systems, because they found that human error is the cause of $70-90 \%$ of all transport accidents. The study conducted by Merritt (2011) contributes to the literature on automation reliance by illuminating the influences of user moods and emotions on the reliance on automated systems. Both trust and liking have been demonstrated to be significant variables in human interactions with increasingly complex technologies. Liking for a new system may be key to appropriate reliance, particularly early in the task. Positive affect can be easily induced and may be a lever for increasing liking.

Sauer et al. (2012) in their study compared two forms of adaptive automation (where the automated system flexibly allocates tasks between human and machine) with adaptable automation (where the human allocates the tasks). It emerged that participants under adaptable automation adopted a more active system management strategy and reported higher levels of self-confidence than in the adaptive control mode. Furthermore, the results showed higher levels of perceived workload, fatigue and anxiety for performance-based adaptive automation control than the other two modes. This is of relevance, given that this automation mode may also be easier to design.

McBride et al. (2014) recognised that automation has the potential to aid humans with a diverse set of tasks and support overall system performance. On the other hand, automated systems are not always reliable, which is why humans need to be actively involved in the process of discovering, understanding and correcting errors. Nevertheless, the authors point out that the process of error management in the context of human-automation interaction is not well understood. For this purpose, their scientific paper examined relevant research in human-automation interaction and human error to identify critical automation, person, task and emergent variables. Hancock (2014) points out that the trend towards increasing automation continues, but also expresses concerns about excessive process automation. Much like earlier studies on the subject, he speculates that the existence of automated technological support might actually inhibit the growth of knowledge on behalf of the human operator. He therefore proposes that the solution for determining the optimum level of automation is to find a middle ground.

Everitt et al. (2015) point out that, as automation technology becomes more intelligent, so does the capacity of automation to supplement not only the physical, but also the perceptual and cognitive aspects of a task. Tasks that were previously the exclusive domain of skilled human operators can now be supplemented or replaced by intelligent automation. However, they also point out that there is no formal methodology to determine 
what tasks are suitable for intelligent automation, and to what extent they can or should be automated. Rovira et al. (2016) in their study confirm the important role of working memory ability in the use of automation: individuals with high working memory ability seem most able to perform the task and evaluate the automation by appropriately calibrating their trust, while those lower in working memory ability inappropriately calibrate their trust and rely on automation, even when it is incorrect.

Sauer et al. (2016) examined the effects of operators' exposure to various types of automation failures in training. The results showed that automation bias was very high when operators trained on miss-prone automation encountered a failure of the diagnostic system. Operator errors resulting from automation bias were much higher when automation misdiagnosed a fault than when it missed one. Differences in trust levels that were instilled by the different training experiences disappeared during the testing session. Ryu et al. (2016) built a model, which proposes an integrated representation of human operator's action choices when modelling human-machine interaction systems, which can be used to determine when the human operator's intervention can (or cannot) be preferred in the automated system design. The goal of the proposed model is to more effectively model probabilistic human decision-making behaviour based on knowledge retrieval and action selection based on past experience.

Chavaillaz et al. (2016) evaluate operator performance, trust, and use of adaptable automation under different reliability levels. The findings suggest no simple relationship between trust and automation reliance. While system reliability affected trust, it did not have an influence on automation reliance, which may be due to behavioural norms being established during training. To overcome this, it may be helpful to train operators on all known automation failures, which would provide them with a better understanding of the strengths and weaknesses of the automatic system. As a consequence, a better match may be observed between operator reliance and trust in automation.

Cochran et al. (2017) proposes a systematic approach to model human-machine interactions in supervisory control of machining operations; it characterises the coexistence of machines and humans for an enterprise to balance the goals of automation/productivity and flexibility/agility. The proposed model can be used to design production systems at different levels of an enterprise architecture, particularly at the machine level in a production system where operators interact with semiautomation.

Pacaux-Lemoine et al. (2017) examine Intelligent Manufacturing Systems, in which processes have become so autonomous that humans are unaware of the processes running, while they may need to intervene to update the manufacturing plan or modify the process configuration if a machine breaks down, or to assist process-intelligent entities when they find themselves in a deadlock.
They highlights the lack of attention paid to the correct integration of humans in Intelligent Manufacturing Systems and provides solutions based on human-machine cooperation principles to retain humans in the process control loop with different levels of involvement identified by the levels of automation.

In recent years, we have seen great progress made in the development of modern warehouse solutions, as well as a dramatic rise in research on the issues related to the introduction of modern technology and interaction between operators and automation (Tsarouchi et al. 2016). However, a look at some of the existing studies on the usefulness of the use of modern technology and therefore greater automation reveals that their conclusions are often contradictory. The prevailing position is that the use of modern technology is an effective response to constant customer needs for quality logistics processes in the supply chain. Not taking advantage of the benefits brought about by the successful automation of the warehouse process underlines the drawbacks and dilemmas about the usefulness of the use of technology. This aspect is especially highlighted by studies that are sceptical of the excessive impact of automation on work processes. To this purpose, the following scientific question was formulated:

Are companies that are suppliers to the international automotive industry taking advantage of the benefits of using modern warehouse technologies?

The basic scientific question will be examined with the following hypotheses:

- H1: basic warehouse equipment are not reliable, which is why suppliers in the automotive industry rarely use them;

- H2: modern warehouse systems are reliable, which is why they are often used by suppliers in the automotive industry, due to increased demand for data processing;

- H3: the perception of the safety of use of warehouse technology in businesses using modern technology is different than in companies that do not use modern technology;

- H4: the management of a company that uses modern technology reacts differently to warehouse errors than the management of a company that does not use modern technologies.

Fig. 1 shows the research model. The formulation of the first two hypotheses is based on the assumption that the warehouse process is changing along with the introduction of automation. The third hypothesis highlights the impact of employee perceptions about the usefulness of modern warehouse technology, as employee perceptions can represent one of the first obstacles to the increased automation of the warehouse process. The fourth hypothesis is intended to determine whether the management of a company that uses modern technology reacts differently to warehouse errors than the management of a company that does not use modern technology. 
WAREHOUSE TECHNOLOGY APPLIED BY A SUPPLIER IN THE AUTOMOTIVE INDUSTRY

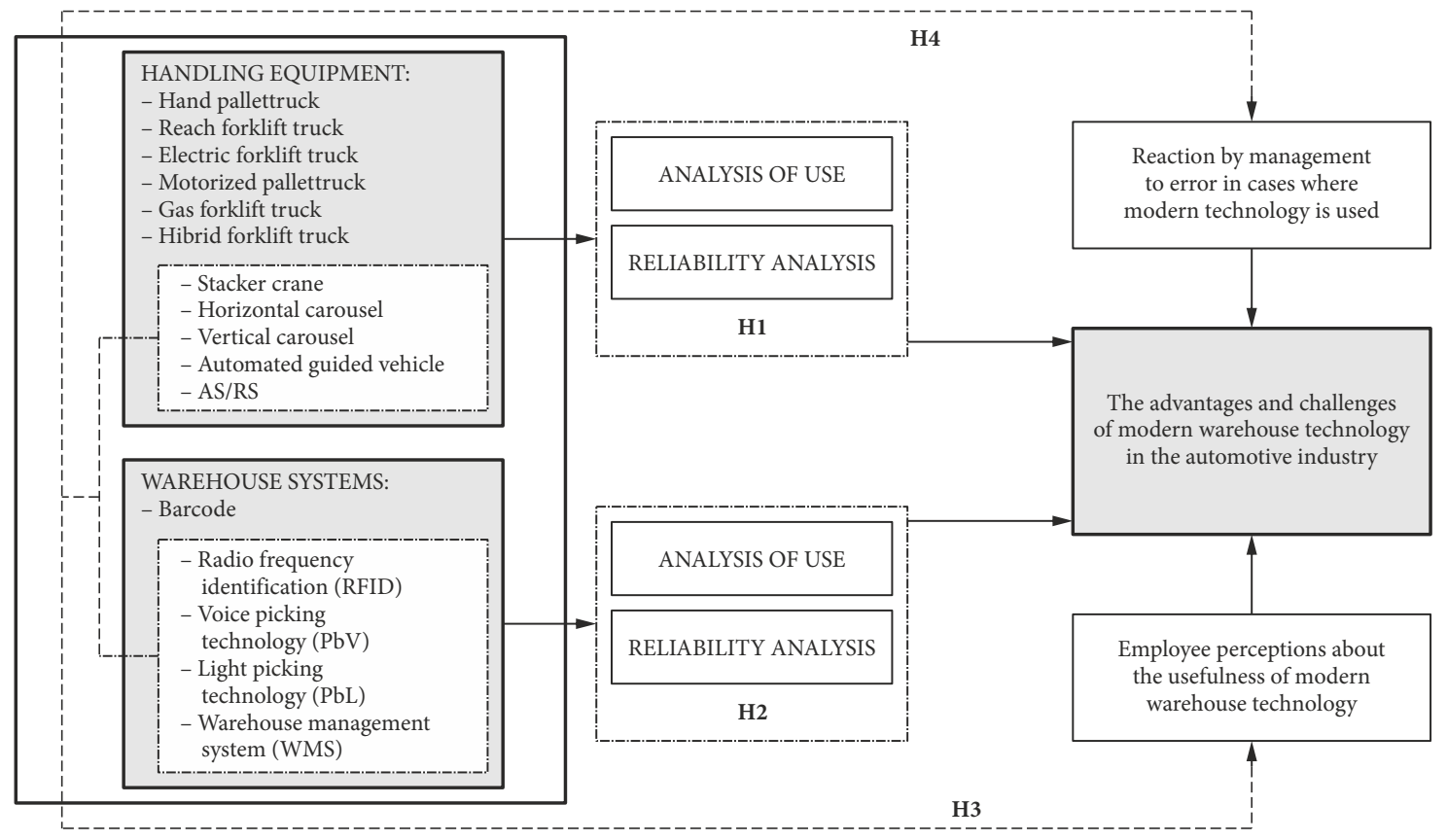

Fig. 1. Research model

\section{Methodology}

The survey was developed in cooperation with the Automotive Cluster of Slovenia (ACS), which is a business association based on economic interest, uniting Slovenian automotive suppliers and manufacturers, with the goal of strengthening their competitiveness and creating greater added value.

The ACS provides support to its members to help them integrate into the global automotive industry through joint promotional activities and high-tech products. To this end, the ACS promotes the efficiency of its members by providing adequate research and by cooperating with expert development and scientific institutions both in Slovenia and abroad.

Out of the 35 companies operating in the Slovenian automotive industry that were asked to take part in the survey, 11 companies opted not to participate. The final sample was comprised of 24 companies. The companies that constitute the sample for the survey generate a total of 2.2 billion EUR in annual revenues and collectively employ over 14000 employees. For the purpose of the survey, an online questionnaire was set up, which was forwarded to the management of each company, following an invitation (in writing and by telephone) to take part in the survey. The online questionnaire was composed of two parts. The first part of the questionnaire consisted of four general questions about the company. The second part of the online questionnaire consisted of twenty questions designed to assess the reliability of the warehouse process, identify the warehousing operations most subject to errors, determine the main causes of injury in the warehouse, the usefulness of the handling equipment and warehouse systems used for warehousing with an assessment of the frequency of errors, and an evaluation of management's tendency to introduce warehousing technologies. The questionnaire was mainly completed by warehouse managers who were contacted previously to clarify any dilemmas that might arise in completing the questionnaire.

Frequencies and percentages were calculated for categorical variables, median and range for ordinal, and mean as standard deviation for numeric variables. The association between two categorical variables was tested by the likelihood ratio test; as expected frequencies were lower than 5 . The Wilcoxon matched pairs test was used to test the difference in distribution between two dependent samples. The effect size was calculated as proposed by Rosenthal (1994) as $r=z / \sqrt{n}$.

The effect size was interpreted as small when its value was 0.1 , as medium when its value was 0.3 and as large when it was 0.5 or higher. An independent sample t-test was used to test the difference in managerial reactions to mistakes between companies using basic and modern warehouse technology. Factor analysis was used to reduce the number of variables (items) measuring managerial reactions to mistakes. It showed that the analysis of mistakes in regular meetings with team work and team solutions form a single factor in management reactions to warehouse mistakes. Disciplinary procedure and monetary punishment form a separate factor. Two composite measures for each management approach towards mistakes handling are formed as the average of items forming each of the factors. A statistical analysis was performed in SPSS version 22.0. The significance level was set to $\alpha=0.05$ (two-tailed). 


\section{Results}

Out of $n=24$ companies, 15 (62.5\%) perceive mistakes in warehouse as easily made (Table 1$)$. The operations most sensitive to mistakes are picking $(n=7 ; 29.2 \%)$ and inventory control $(n=6 ; 25 \%)$. The most common reason for injury is manual handling $(n=19 ; 79.2 \%)$.

The results that pertain to the first hypothesis $(\mathrm{H} 1)$ are shown in Table 2. The object is to determine the reliability of basic warehouse equipment and the frequency of its use. Mistakes using equipment that is frequently used are rare (maximum median value is 2 standing for 'rarely'). It is expected that with the frequent usage of a particular piece of equipment, the number of mistakes increases. However, a situation with frequent use and fewer mistakes is preferable. To test whether there is a statistically significant difference between usage and mistakes frequency for a given piece of equipment, the Wilcoxon matched pairs test was used.

The results show that statistically significant difference exists between usage and mistake frequency for all the more commonly used pieces of equipment. In all cases, the frequency of mistakes is lower than the frequency of use, suggesting that the equipment is safe for use. The discrepancy between the frequency of use and the frequency of mistakes is described by the effect size. In all cases, the effect size is above 0.5 , showing large effect and therefore high discrepancy.

The largest effect was noted for the hand pallet truck $(r=0.81)$, suggesting it is the safest piece of equipment, followed by the electric forklift truck $(r=0.73)$, the reach forklift truck, the motorised pallet lifter $(r=0.71)$ and the gas forklift truck $(r=0.66)$ as the least safe of all (but still quite safe). The most frequently used warehouse handling equipment are the hand pallet truck, the reach forklift truck, the electric forklift truck, the motorised pallet lifter and the gas forklift truck. Rarely or never used are the stacker crane, the horizontal carousel, the vertical carousel, the hybrid forklift truck, the AGV and the AS/RS (Table 2).
Table 1. Frequency of mistakes, types of mistakes and reasons for injury in a warehouse

\begin{tabular}{|l|c|}
\multicolumn{2}{|c|}{ Making mistakes easily } \\
\hline \multicolumn{2}{|c|}{ Mistakes by warehousing operations } \\
\hline Showing lower agreement & $9(37.5)$ \\
\hline Showing higher agreement & $7(62.5)$ \\
\hline \multicolumn{2}{|c|}{$7(29.2)$} \\
\hline Picking & $6(25.0)$ \\
\hline Inventory control & $3(12.5)$ \\
\hline Shipping & $3(12.5)$ \\
\hline Packing & $2(8.3)$ \\
\hline Receiving & $2(8.3)$ \\
\hline Put away & $1(4.2)$ \\
\hline Storing & $19(79.2)$ \\
\hline & $2(8.3)$ \\
\hline Manual handling & $1(4.2)$ \\
\hline Hit by a moving vehicle & $1(4.2)$ \\
\hline Slip & $1(4.2)$ \\
\hline Falls from height & $8(33.3)$ \\
\hline Hit by moving, falling object &
\end{tabular}

The next hypothesis (H2) is aimed at determining whether suppliers in the automotive industry frequently use modern warehouse systems because of the increased demand for data processing and whether these systems are reliable (Table 3). Amongst all the warehouse systems, Barcode technology is used most frequently, while others are rarely or never used (Table 3). The effect size suggests that Barcode technology is safe for use and that its use results in a low mistakes rate.

In verifying the third hypothesis (H3), the analysis takes a step further by determining whether the perception of the safety of use of warehouse technology in businesses using modern technology differs from that in companies that do not use modern technology.

Table 2. Usage and mistakes frequency by warehouse handling equipment

\begin{tabular}{|l|c|c|c|c|c|}
\hline \multicolumn{1}{c}{$\begin{array}{c}\text { Warehouse handling } \\
\text { equipment }\end{array}$} & Usage frequency & Mistakes frequency & \multicolumn{2}{c|}{ Wilcoxon test } & Effect size \\
\cline { 2 - 7 } & Median (range) & Median (range) & $Z$ & $p$ & $r$ \\
\hline Hand pallet truck & $4(2-5)$ & $2(1-5)$ & -3.99 & $<0.001$ & 0.81 \\
\hline Reach forklift truck & $4(1-5)$ & $2(1-5)$ & -3.49 & $<0.001$ & 0.71 \\
\hline Electric forklift truck & $5(1-5)$ & $2(1-4)$ & -3.60 & $<0.001$ & 0.73 \\
\hline Motorised pallet lifter & $4(1-5)$ & $1.5(1-4)$ & -3.46 & 0.001 & 0.71 \\
\hline Gas forklift truck & $4.5(1-5)$ & $1.5(1-5)$ & -3.21 & 0.001 & 0.66 \\
\hline Stacker crane & $1(1-5)$ & $1(1-5)$ & -2.23 & 0.03 & 0.46 \\
\hline Horizontal carousel & $1(1-4)$ & $1(1-3)$ & -1.63 & 0.10 & 0.33 \\
\hline Vertical carousel & $1(1-4)$ & $1(1-3)$ & -1.41 & 0.16 & 0.29 \\
\hline Hybrid forklift truck & $1(1-5)$ & $1(1-3)$ & -1.00 & 0.32 & 0.20 \\
\hline AGV & $1(1-4)$ & $1(1-2)$ & -1.34 & 0.18 & 0.27 \\
\hline AS/RS & $1(1-5)$ & $1(1-5)$ & -1.41 & 0.16 & 0.29 \\
\hline
\end{tabular}

Notes: ${ }^{\star} p-p$-value; usage and mistakes frequency were measured on a 5 -point scale $(1-$ never; 5 - very frequent). 
Table 3. Usage and mistakes frequency by warehouse systems

\begin{tabular}{|l|c|c|c|c|c|}
\hline \multirow{2}{*}{$\begin{array}{c}\text { Warehouse } \\
\text { systems }\end{array}$} & $\begin{array}{c}\text { Usage } \\
\text { frequency }\end{array}$ & $\begin{array}{c}\text { Mistakes } \\
\text { frequency }\end{array}$ & \multicolumn{2}{|l|}{ Wilcoxon test } & $\begin{array}{c}\text { Effect } \\
\text { size }\end{array}$ \\
\cline { 2 - 6 } & $\begin{array}{c}\text { Median } \\
\text { (range) }\end{array}$ & $\begin{array}{c}\text { Median } \\
\text { (range) }\end{array}$ & $Z$ & $p$ & $r$ \\
\hline RFID & $1(1-5)$ & $1(1-2)$ & -2 & 0.042 & 0.41 \\
\hline $\mathrm{PbV}$ & $1(1-1)$ & $1(1-1)$ & 0 & 1.000 & 0.00 \\
\hline $\mathrm{PbL}$ & $1(1-2)$ & $1(1-1)$ & -1 & 0.317 & 0.20 \\
\hline Barcode & $5(1-5)$ & $2(1-5)$ & -4 & $<0.001$ & 0.80 \\
\hline WMS & $1.5(1-5)$ & $1(1-5)$ & -2 & 0.014 & 0.50 \\
\hline
\end{tabular}

Notes: ${ }^{*} p$ - $p$-value; usage and mistakes frequency were measured on a 5 -point scale ( 1 - never; 5 - very frequent).

Companies were sorted into two groups by the usage frequency of modern technical equipment and warehouse systems. Companies using handling equipment such as stacker crane, horizontal or vertical carousel, AGV or AS/RS and RFID, PbV, PbL or WMS, formed a group of companies using modern warehouse technology. All other companies formed a group using basic warehouse technology. The two groups of companies were compared in their perception of how easily mistakes can occur (Table 4$)$. The majority ( $n=13 ; 92.9 \%)$ of companies using basic warehouse technology agree to a higher extent that mistakes in a warehouse can occur easily. On the other hand, eight ( $80 \%)$ companies using modern technology think that mistakes do not occur as easily. The difference in perception is statistically significant $(L R(1)=14.5 ; p<$ 0.001; Table 4).
Table 4. Type of technology used and mistakes occurrence perception

\begin{tabular}{|c|c|c|c|c|}
\hline \multirow{2}{*}{$\begin{array}{c}\text { Making mistakes } \\
\text { easily }\end{array}$} & \multicolumn{2}{|c|}{$\begin{array}{c}\text { Use of warehouse } \\
\text { technology }\end{array}$} & \multirow{2}{*}{$L R(d f)$} & $p$ \\
\cline { 2 - 3 } & Basic & Modern & & \\
\hline Agree to lower extent & $1(7.1)$ & $8(80)$ & \multirow{2}{*}{$14.54(1)$} & $<0.001$ \\
\hline Agree to higher extent & $13(92.9)$ & $2(20)$ & & \\
\hline
\end{tabular}

Notes: ${ }^{*} L R$ - likelihood ratio statistics; $d f$ - degree of freedom; $p-p$-value.

The last hypothesis (H4) is designed to determine whether the management of a company that uses modern technology reacts differently to warehouse errors than the management of a company that does not use modern technologies (Table 5). Analysis showed no statistically significant differences in management reaction when mistakes occur between companies according to the type of technology used.

\section{Discussion}

The results of the study confirm that errors can occur quite easily during warehousing operations, which places warehousing among the activities that must have a great number of systems in place to ensure the safety and quality of work processes. An analysis of the results of the first hypothesis shows that basic warehouse equipment is reliable and often used by suppliers in the automotive industry. The results therefore do not corroborate previous findings (Berger, Ludwig 2007; Rich-

Table 5. Management reaction to mistakes by type of warehouse technology used

\begin{tabular}{|c|c|c|c|}
\hline Use of warehouse handling equipment and warehouse systems & $n$ & Mean $(S D)$ & $p$-value \\
\hline \multicolumn{4}{|c|}{ Errors are discussed at regular meetings } \\
\hline Basic warehouse technology & 14 & $3.9(0.9)$ & 0.559 \\
\hline Modern warehouse technology & 10 & $3.6(1.3)$ & - \\
\hline \multicolumn{4}{|c|}{ The causes of each error are analysed together } \\
\hline Basic warehouse technology & 14 & $3.9(0.7)$ & 0.559 \\
\hline Modern warehouse technology & 10 & $3.7(1.2)$ & - \\
\hline \multicolumn{4}{|c|}{ The causes for future errors are eliminated together } \\
\hline Basic warehouse technology & 14 & $4(0.8)$ & 0.772 \\
\hline Modern warehouse technology & 10 & $3.9(0.9)$ & - \\
\hline \multicolumn{4}{|c|}{ Team approach factor (composite measure) } \\
\hline Basic warehouse technology & 14 & $3.9(0.7)$ & 0.560 \\
\hline Modern warehouse technology & 10 & $3.7(0.9)$ & - \\
\hline \multicolumn{4}{|c|}{ In case of error the person responsible faces disciplinary action } \\
\hline Basic warehouse technology & 14 & $2(1)$ & 0.275 \\
\hline Modern warehouse technology & 10 & $2.4(0.7)$ & - \\
\hline \multicolumn{4}{|c|}{ In case of error the person responsible is subjected to a financial penalty } \\
\hline Basic warehouse technology & 14 & $1.6(1)$ & 0.685 \\
\hline Modern warehouse technology & 10 & $1.8(0.8)$ & - \\
\hline \multicolumn{4}{|c|}{ Punishment factor (composite measure) } \\
\hline Basic warehouse technology & 14 & $1.8(0.9)$ & 0.427 \\
\hline Modern warehouse technology & 10 & $2.1(0.6)$ & - \\
\hline
\end{tabular}


ards 2014; Myerson 2012; Mangan, Lalwani 2016) that suggested that the warehouse process is changing due to the reduced number of manual handling operations. By contrast, Slovenian suppliers in the international automotive industry decisively opt for manual handling, especially the use of basic handling equipment. Hypothesis (H1) is thereby rejected. As for answering the scientific question, the findings indicate that companies are not making use of the advantages of modern handling equipment, which can complicate work in a warehouse from a technological point of view and, above all, from the point of view of safety. In the analysed sample, most warehouse injuries occur during manual handling operations, which can be indirectly linked to the prevalent use of basic handling equipment.

Modern warehouse systems are reliable, yet they are rarely used by suppliers in the automotive industry. The results of the second hypothesis do not confirm previous theoretical knowledge, according to which the warehouse process is changing due to increased demand for data processing. Warehouse operators in companies in the Slovenian automotive industry thus interact more with the physical movement of goods - a result that had been already suggested by the first hypothesis. The second hypothesis (H2) is also only partially confirmed.

The results of the first two hypotheses suggest that the automation of warehouse processes of Slovenian suppliers in the international automotive industry is at a low technological level. The most commonly used is Barcode technology, which does not fall under modern technological solutions, since it has been in use for more than 40 years. RFID technology - the modern successor to the Barcode - is not used by any of the companies. The same applies to $\mathrm{PtL}$ in $\mathrm{PbV}$ technologies. This points to the potential vulnerabilities of the picking process and the process of inventory control in terms of the errors that may occur. More than half of all the errors in the warehouse process occur during the two aforementioned warehousing operations, as shown in Fig. 2. The overall conclu- sion is that companies are not even attempting to reap the benefits of modern technology solutions, which is a big problem that warrants a more detailed discussion.

The trends of participation in the automotive industry demand that suppliers continuously improve their business processes and maintain a high level of innovation, which is directly linked to the introduction of modern technology solutions in the warehouse process. For this reason, it is surprising and perhaps worrying that Slovenian suppliers in the automotive industry so rarely opt to implement modern warehouse technology. Perhaps time will bring change and a greater use of modern warehouse technologies, as suggested by the results of the third hypothesis.

These results $(\mathrm{H} 3)$ demonstrate that the perception of the safety of use of warehouse technology by businesses using modern technology is significantly greater than in companies that do not use modern technology. In companies that use basic warehousing technology, 93\% of warehouse managers believe that the technological equipment that is currently in use is the main reason why errors occur during the execution of work activities in a warehouse. Warehouse managers in general do not trust basic warehouse technology, although its reliability has been proven. This perception can increase the level of stress amongst warehouse staff, if those who work with equipment are aware of the fact that they are using equipment known to increase the probability of errors. These findings are an important indication for the management of companies that are not using modern technology, that they should modernise their warehouse processes by adding technology. The companies that currently use modern technology display a positive attitude towards its usefulness, which is a clear indication that there is a need for the implementation and use of modern warehouse technologies by the Slovenian suppliers of the international automotive industry. These findings should also lead to less resistance when a company's management decides to implement modern technology solutions in the warehouse.

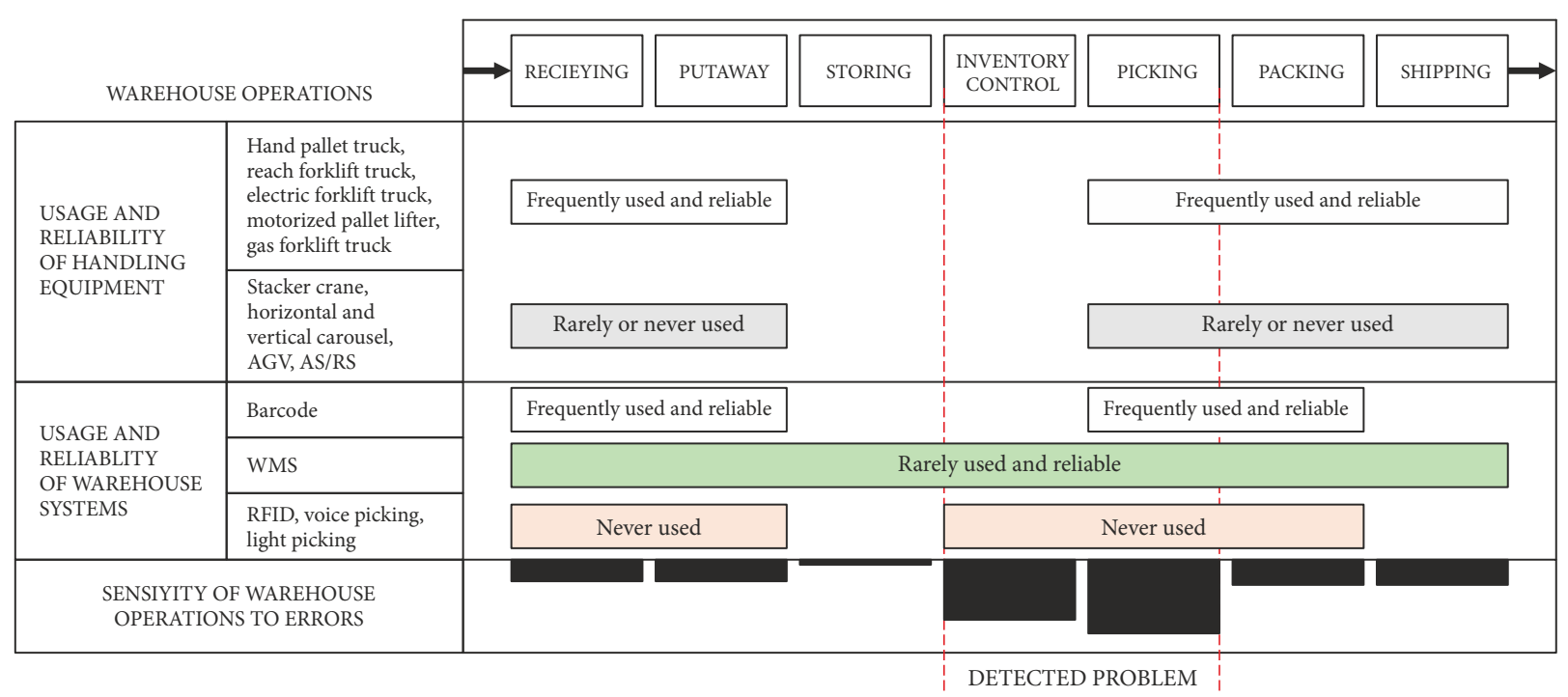

Fig. 2. The usage and reliability of warehouse technology in the slovenian automotive industry 
The fourth hypothesis (H4) was used to determine whether the reaction to warehouse errors by the management of a company that uses modern technology differs from the reaction by the management of a company that does not use modern technology. The results did not yield statistically significant differences, which could suggest that all the companies in the sample take the same organisational approach when an error occurs. It should be also pointed out that, in companies that do not use modern technology, employees do not feel the additional pressure of having to face financial or disciplinary punishment, whenever an error is made. Nevertheless, the fourth hypothesis is rejected.

The research results cannot be generalised to the entire automotive industry, because they relate to the case study of the automotive industry in a small country such as Slovenia. Nevertheless, they provide important insights into understanding the benefits and dilemmas connected to the use of modern warehouse technologies, since Slovenian companies have a long tradition of participation in the international automotive industry. The results are relevant for both the academic and managerial communities, particularly in smaller countries in Central and Eastern Europe, where the supply sector of the automotive industry is growing in size and scope with each year. The following findings are especially significant:

- the research findings provide an answer to the main scientific question and confirm that Slovenian companies that are suppliers to the international automotive industry do not benefit from using modern warehouse technologies. More than $60 \%$ of the companies in the sample do not use any of the available modern technological solutions in warehouse management, which could put them at a disadvantage against competitors in the demanding sector of the automotive industry in the medium term;

- the results suggest that the biggest obstacle to implementing modern warehouse technology in the Slovenian automotive industry is corporate immaturity. Companies mostly use basic warehouse technology, despite the fact that such technology does not ensure a sense of safety in the warehouse;

- the results represent an important piece of information for management staff, since the questionnaire was completed by warehouse managers who are the basic indicators of the need for changes and improvements in the warehouse. Management staff will be able to better understand the process of warehouse automation. This will enable them to design better warehouse systems, as the analysis has shown that the use of modern warehouse technology is necessary in certain warehousing operations and that modern technology is underused, considering its benefits;

- the results should be helpful in targeted employee training in procedures that have the purpose of ensuring safety and health at work during the most sensitive warehousing operations. It is also one of the ways in which companies can limit the impact of human errors in the warehouse process of the company;

- the impact of the study on achieving a more balanced use of automation in warehousing operations is also significant. This allows companies to spend less on warehouse equipment and modern warehouse systems, as it enables them to implement warehouse technology only for those warehousing operations that would benefit the most from it;

- the study represents an important analysis for domestic and international providers of modern warehouse technology. First and foremost, in terms of sales volume, since even a small country like Slovenia holds an important sales potential (the companies in the sample represent a total of 14000 employees and 2.2 billion EUR annual revenues). A particularly significant aspect is the lack of trust exhibited by the companies towards basic warehouse technology, combined with their reluctance to procure modern warehouse technology. Moreover, the results of the study will release the providers of technologies such as WMS, RFID, PbV and PbL from the necessity of convincing companies of the usefulness of modern warehouse technology. The results can also be utilised in further activities aimed at improving the application of technology in the picking process;

- an overview and analysis of the use of technology in the warehouse process provides important empirical support for the improvement of logistics processes in the supply chains of suppliers in the automotive industry;

- the present study synthesises the literature in the field of usability and reliability of modern warehouse technology, which represents an important framework for future empirical studies.

\section{Conclusions}

The present study represents one of the first contributions to include an analysis of the usage and reliability of warehouse technologies in supply companies in the automotive industry. The results are relevant for both the academic and managerial communities, particularly in smaller countries in Central and Eastern Europe, where the supply sector of the automotive industry is growing in size and scope with each year. The findings provide a clear answer to the main scientific question, as $60 \%$ of the companies interviewed are not reaping any of the benefits of modern warehouse solutions.

These companies also have a negative attitude towards basic warehouse technology, which can result in poorer working conditions in the medium term.

The study also provides a starting point for understanding human use of warehouse technology, which 
can lead to improvements in the design of warehouse systems, more effective employee training methods and more sensible and balanced warehousing process automation policies.

The study is limited to Slovenian suppliers of the international automotive industry, which can restrict generalisation of the findings to other empirical contexts. In the future, it would be sensible to carry out a similar study in comparable countries in Central and Eastern Europe and compare the results.

\section{References}

Apsalons, R.; Gromov, G. 2017. Using the min/max method for replenishment of picking locations, Transport and Telecommunication Journal 18(1): 79-87.

https://doi.org/10.1515/ttj-2017-0008

Atieh, A. M.; Kaylani, H.; Al-Abdallat, Y.; Qaderi, A.; Ghoul, L.; Jaradat, L.; Hdairis, I. 2016. Performance improvement of inventory management system processes by an automated warehouse management system, Procedia CIRP 41: 568572. https://doi.org/10.1016/j.procir.2015.12.122

Bainbridge, L. 1983. Ironies of automation, Automatica 19(6): 775-779. https://doi.org/10.1016/0005-1098(83)90046-8

Berger, S. M.; Ludwig, T. D. 2007. Reducing warehouse employee errors using voice-assisted technology that provided immediate feedback, Journal of Organizational Behavior Management 27(1): 1-31.

https://dx.doi.org/10.1300/J075v27n01_01

Bohács, G.; Frikker, I.; Kovács, G. 2013. Intermodal logistics processes supported by electronic freight and warehouse exchanges, Transport and Telecommunication Journal 14(3): 206-213. https://doi.org/10.2478/ttj-2013-0017

Chavaillaz, A.; Wastell, D.; Sauer, J. 2016. System reliability, performance and trust in adaptable automation, Applied Ergonomics 52: 333-342.

https://doi.org/10.1016/j.apergo.2015.07.012

Cochran, D. S.; Arinez, J. F.; Collins, M. T.; Bi, Z. 2017. Modelling of human-machine interaction in equipment design of manufacturing cells, Enterprise Information Systems 11(7): 969-987.

De Felice, F; Petrillo, A. 2011. Methodological approach for performing human reliability and error analysis in railway transportation system, International Journal of Engineering and Technology 3(5): 341-353.

De Vries, J.; De Koster, R.; Stam, D. 2016. Exploring the role of picker personality in predicting picking performance with pick by voice, pick to light and RF-terminal picking, International Journal of Production Research 54(8): 2260-2274. https://doi.org/10.1080/00207543.2015.1064184

Dekker, S. 2017. The Field Guide to Understanding Human Error. CRC Press. 236 p.

Dybskaya, V.; Sverchkov, P. 2017. Designing a rational distribution network for trading companies, Transport and Telecommunication Journal 18(3): 181-193.

https://doi.org/10.1515/ttj-2017-0016

Everitt, J.; Fletcher, S.; Caird-Daley, A. 2015. Task analysis of discrete and continuous skills: a dual methodology approach to human skills capture for automation, Theoretical Issues in Ergonomics Science 16(5): 513-532. https://doi.org/10.1080/1463922X.2015.1028508

Gaukler, G. M.; Seifert, R. W. 2007. Applications of RFID in supply chains, in H. Jung, B. Jeong, F. F. Chen (Eds.).
Trends in Supply Chain Design and Management: Technologies and Methodologies, 29-48.

https://doi.org/10.1007/978-1-84628-607-0_2

Hancock, P. A. 2014. Automation: how much is too much?, Ergonomics 57(3): 449-454.

https://doi.org/10.1080/00140139.2013.816375

Janilionis, V. V.; Bazaras, Ž; Janilionis, V. 2016. Comparison of routing algorithms for storage and retrieval mechanism in cylindrical AS/RS, Transport 31(1): 11-21.

https://doi.org/10.3846/16484142.2014.995130

Kajackas, A.; Žuraulis, V.; Sokolovskij, E. 2015. Influence of VANET system on movement of traffic flows in emergency situations, Promet - Traffic \& Transportation 27(3): 237-246. https://doi.org/10.7307/ptt.v27i3.1612

Kłodawski, M.; Jacyna, M.; Lewczuk, K.; Wasiak, M. 2017. The issues of selection warehouse process strategies, Procedia Engineering 187: 451-457. https://doi.org/10.1016/j.proeng.2017.04.399

Kolarovszki, P.; Kolarovszká, Z.; Perakovic, D.; Periša, M. 2016. Laboratory testing of active and passive UHF RFID tags, Transport and Telecommunication Journal 17(2): 144-154. https://doi.org/10.1515/ttj-2016-0014

Mangan, J.; Lalwani, C. 2016. Global Logistics and Supply Chain Management. 3rd edition. Wiley. 416 p.

Marchet, G.; Melacini, M.; Perotti, S. 2015. Investigating order picking system adoption: a case-study-based approach, International Journal of Logistics Research and Applications: $a$ Leading Journal of Supply Chain Management 18(1): 82-98. https://doi.org/10.1080/13675567.2014.945400

McBride, S. E.; Rogers, W. A.; Fisk, A. D. 2014. Understanding human management of automation errors, Theoretical Issues in Ergonomics Science 15(6): 545-577.

https://doi.org/10.1080/1463922X.2013.817625

Merritt, S. M. 2011. Affective processes in human-automation interactions, Human Factors: the Journal of the Human Factors and Ergonomics Society 53(4): 356-370. https://doi.org/10.1177/0018720811411912

Min, H. 2006. The applications of warehouse management systems: an exploratory study, International Journal of Logistics Research and Applications: a Leading Journal of Supply Chain Management 9(2): 111-126. https://doi.org/10.1080/13675560600661870

Myerson, P. 2012. Lean Supply Chain and Logistics Management. McGraw-Hill Education. 288 p.

Nathanail, E.; Gogas, M.; Adamos, G. 2016. Assessing the contribution of urban freight terminals in last mile operations, Transport and Telecommunication Journal 17(3): 231-241. https://doi.org/10.1515/ttj-2016-0021

Ngai, E. W. T.; To, C. K. M.; Moon, K. K. L.; Chan, L. K.; Yeung, P. K. W.; Lee, M. C. M. 2010. RFID systems implementation: a comprehensive framework and a case study, International Journal of Production Research 48(9): 25832612. https://doi.org/10.1080/00207540903564942

Norman, D. A. 1990. The 'problem' with automation: inappropriate feedback and interaction, not 'over-automation', Philosophical Transactions of the Royal Society B: Biological Sciences 327(1241): 585-593.

https://doi.org/10.1098/rstb.1990.0101

Pacaux-Lemoine, M.-P.; Trentesaux, D.; Rey, G. Z.; Millot, P. 2017. Designing intelligent manufacturing systems through human-machine cooperation principles: a human-centered approach, Computers \& Industrial Engineering (in Press). https://doi.org/10.1016/j.cie.2017.05.014 
Palšaitis, R.; Čižiūnienė, K.; Vaičiūtè, K. 2017. Improvement of warehouse operations management by considering competencies of human resources, Procedia Engineering 187: 604-613. https://doi.org/10.1016/j.proeng.2017.04.420

Pyza, D.; Jachimowski, R.; Jacyna-Gołda, I.; Lewczuk, K. 2017. Performance of equipment and means of internal transport and efficiency of implementation of warehouse processes, Procedia Engineering 187: 706-711. https://doi.org/10.1016/j.proeng.2017.04.443

Reason, J. 2009. Human Error. Cambridge University Press. $320 \mathrm{p}$.

Reason, J. 1997. Managing the Risks of Organizational Accidents. Ashgate. 252 p.

Rekik, Y.; Sahin, E.; Dallery, Y. 2008. Analysis of the impact of the RFID technology on reducing product misplacement errors at retail stores, International Journal of Production Economics 112(1): 264-278. https://doi.org/10.1016/j.ijpe.2006.08.024

Richards, G. 2014. Warehouse Management: a Complete Guide to Improving Efficiency and Minimizing Costs in the Modern Warehouse. 2nd edition. Kogan Page. 448 p.

Rosenthal, R. 1994. Parametric measures of effect size, in H. Cooper, L. V. Hedges (Eds.). The Handbook of Research Synthesis, 231-244.

Rovira, E.; Pak, R.; McLaughlin, A. 2016. Effects of individual differences in working memory on performance and trust with various degrees of automation, Theoretical Issues in Ergonomics Science (in Press). https://doi.org/10.1080/1463922X.2016.1252806

Ryu, H.; Kim, N.; Lee, J.; Shin, D. 2016. An affordance-based model of human action selection in a human-machine interaction system with cognitive interpretations, International Journal of Human-Computer Interaction 32(5): 402-414. https://doi.org/10.1080/10447318.2016.1157678

Sauer, J.; Chavaillaz, A.; Wastell, D. 2016. Experience of automation failures in training: effects on trust, automation bias, complacency and performance, Ergonomics 59(6): 767-780. https://doi.org/10.1080/00140139.2015.1094577

Sauer, J.; Kao, C.-S.; Wastell, D. 2012. A comparison of adaptive and adaptable automation under different levels of environmental stress, Ergonomics 55(8): 840-853. https://doi.org/10.1080/00140139.2012.676673

Schmidt, M.; Thoroe, L.; Schumann, M. 2013. RFID and barcode in manufacturing logistics: interface concept for concurrent operation, Information Systems Management 30(2): 100-115. https://doi.org/10.1080/10580530.2013.773801

Tajima, M. 2007. Strategic value of RFID in supply chain management, Journal of Purchasing and Supply Management 13(4): 261-273.

https://doi.org/10.1016/j.pursup.2007.11.001

Tsarouchi, P.; Makris, S.; Chryssolouris, G. 2016. Human-robot interaction review and challenges on task planning and programming, International Journal of Computer Integrated Manufacturing 29(8): 916-931. https://doi.org/10.1080/0951192X.2015.1130251

Xiao, Y.; Yu, S.; Wu, K.; Ni, Q.; Janecek, C.; Nordstad, J. 2007. Radio frequency identification: technologies, applications, and research issues, Wireless Communications and Mobile Computing 7(4): 457-472. https://doi.org/10.1002/wcm.365 